\title{
Stress and Stroke: Psychological Approach Patients in Middle Hospitalier
}

\section{Dufeil Leyb Rodneil Sounga ${ }^{*}$, Prince Eliot Galieni Sounga Bandzouzi ${ }^{2}$, Alexandre Lemonnier ${ }^{3}$, Johan Leclerc ${ }^{4}$, Charlemagne Simplice Moukouta5, Amal Bernoussi ${ }^{5}$, Jean-William Wallet ${ }^{5}$}

${ }^{1}$ Clinical Research Unit, Beauvais Hospital Center, Beauvais, France

${ }^{2}$ Department of Neurology, Loandjili General Hospital, Pointe-Noire Congo, Faculty of Health Sciences, Marien NGOUABI University, Brazzaville, Congo

${ }^{3}$ Pole of Prevention and Patient Education of Amiens, Amiens University Hospital Center-Picardy, Salouel, France

${ }^{4}$ Amiens University Hospital Center-Picardy, Salouel, France

${ }_{5}^{5}$ CRP-CPO), University of Picardie Jules Verne, UFR Human and Social Sciences, Chemin du Thil—Campus, Amiens, France

Email: *leybrodneil@yahoo.fr, eliotprince2002@yahoo.fr, alexandre.lemonnierpsy@hotmail.com, Leclerc.Johan@chu-amiens.fr, alexandre.lemonnierpsy@hotmail.com, moukouta_cs@hotmail.com, amal.bernoussi@u-picardie.fr,

jean-william.wallet@orange.fr

How to cite this paper: Sounga, D.L.R., Bandzouzi, P.E.G.S., Lemonnier, A., Leclerc, J., Moukouta, C.S., Bernoussi, A. and Wallet, J.-W. (2020) Stress and Stroke: Psychological Approach Patients in Middle Hospitalier. Open Journal of Medical Psychology, 9, 79-88.

https://doi.org/10.4236/ojmp.2020.93007

Received: February 19, 2020

Accepted: May 3, 2020

Published: May 6, 2020

Copyright (C) 2020 by author(s) and Scientific Research Publishing Inc. This work is licensed under the Creative Commons Attribution International License (CC BY 4.0).

http://creativecommons.org/licenses/by/4.0/

\begin{abstract}
Introduction: Human beings are confronted with several trying situations that generate stress. Psychopathological manifestations such as anxiety, anxiety, depression, appear as an imbalance in the personality of individuals. Stroke and its increasing frequency in terms of death but especially morbidity has become one of the leading sources of disability in the world. Its appearance is medically described as caused by vascular risk factors. Our goal was to study the impact of stress on the onset and worsening of a stroke. Methodology: This was the clinical method, the aim of which was to identify any stressful event in the patient's life and its psychological consequences in order to establish a link between the impact of stress and the stroke; of the semi-directive clinical interview in order to leave the subject a great possibility of expression on the themes associated with our objective then the inferential descriptive method for the evaluation of psychological factors using several scales including The CISS and the STAI. The inclusion criteria were the existence of a stroke, and the existence of a good state of cognitive functions. Results: In our summary analysis, it appears that the stroke would result from chronic stress objectively detected by coping from the CISS and the STAI. The most stressful events on the Holmes and Rahe Scale were; on the family level: the death of a loved one, the illness of a loved one, incessant arguments, family tensions, family violence. On a personal level: illness, sentimental disappointment, abandonment; alcohol, drugs; and finally on the professional level, dismissal and professional conflict. Conclusion: Stress is a
\end{abstract}


psychological factor that increases the occurrence of a stroke, but also constitutes a determining disturbing element in patients with one or more vascular risk factors.

\section{Keywords}

Stress, Stroke, Psychological Approach, Coping Strategies, Environmental, Risks Factors

\section{Introduction}

Nowadays, the current social context, marked by several existential faults or stressors or even traumatic situations, is expressed by a psychological suffering, such is the case of a death or a loss of a loved one, divorce, dismissal, unemployment, but also impoverishment, abandonment, rape, theft or loss of emotional objects or material goods, or even collective phenomena related to socio-political disorders such as terrorism, war, delinquency, immigration, drugs, all would be at the origin of pathological stress in women and men, today confronted with particularly pathologies important as neurological, psychiatric and cardiovascular affections of which cerebrovascular accidents [1]. These trying situations would represent, taking into account the singular history of the subject and his personality, he consequences of somatized psychological suffering. Thanks to the work of Cannon and Selye [2] [3] that the concept of stress was born. These works were directed towards the study of the physiological reactions of the organism subjected to situations of stress or emotions.

Cannon's work [2] focused on the effects of emotions, in this case, fear in animals. By placing emotion at the center of the adaptive component, he considered that it was correlated with its physiological functions. In view of the experiments carried out, he observes in particular that under the effect of a violent emotion, the nervous system causes an elevation of the secretion of adrenaline implying in a lasting way the sympathetic nervous system. It is a model, according to Cannon, called homeostatic, that is to say, stress reactions are exhausted with the restoration of the previous balance of the organism. In the opposite direction to this observation, we observe the exhaustion of the subject's organism, through dysfunctional psychological and physiological reactions, giving way to the occurrence of a pathology. As for Selye, he defines stress as a non-specific response that the body gives to any request made to it [3]. It introduces the three phases of the general adaptation syndrome designed more as lines of defense than a reputedly harmful agent. It is about the alarm phase, the resistance phase and finally the exhaustion phase, through which the pathology appears which justifies an organic imbalance of the coping mechanisms in the face of stress.

For Anna Freud [4], stress and trauma, which is the consequence, are considered only at the level of psychic life, which can take two ways of processing lived experience which are: liquidation and development. The disorders result 
from the particular susceptibility as the defense mechanisms that this situation generates. However, he does not consider the psychophysiological dimension that can provide a significant explanation between procedural and declarative memory and the role of the amygdala and the hippocampus. These are structures directly associated with emotion and memory. The latter was unable to establish a bridge between the current neuroses, linked to real situations and the neuroses constructed from the elaboration of the fantasies of an event, that produced by sexual impulses being able to produce a vulnerability. Alexander returns to the question, bringing a new deal, that of the effects of the environment linked to the situation of distress; since the environment corresponds to a set of stimuli like noise. If this change in the environment occurs, it triggers an alarm reaction. So this interaction between the individual and the environment is the source of emotional and physical interpersonal behavior.

Lacour in his work shows the link between stress and cardiovascular disorders [5]. To end the stress reactions, Everson [6] states that "hypertension due to stress is correlated with the increased risk of stroke. For this, they also found that the risk of stroke was $72 \%$ higher in these subjects in this case. Likewise, Faye and Booth [7] [8] stress a negative influence of family tensions on the appearance of risk factors for stroke such as hypertension. According to the WHO, stroke is defined as "the rapid development of localized or global signs of brain dysfunction with symptoms lasting more than 24 hours, which can lead to death, with no other apparent cause than a vascular origin" [9].

Our study is part of a biopsychosocial perspective that takes into account biological, psychological and social data that may explain the appearance of a pathology. In this context, Fischer [10] stipulates: "the biopsychosocial model considers the diversity of psychological, biological and social factors, as each having a decisive action on health and disease". The interest of this reflection is on the one hand, to show as well that intense stress can be considered as a determining psychological factor of risk which intervenes in the occurrence of a stroke; since, from a clinical medical point of view, stroke is caused by risk factors such as high blood pressure, diabetes, overweight or obesity, excess cholesterol, smoking, sedentary lifestyle or lack of physical activity, migraine, etc. On the other hand, it is to understand the specificity that justifies the fact that some people, following a conflictual, stressful or trying situation, produce a stroke while others do not produce it confronted with similar situations. The psychological significance of a stressful event or a distressing situation experienced is decisive in triggering certain psychopathological disorders. This is how our goal was to determine the role of stress in the onset and worsening of a stroke.

\section{Research Methodology}

\subsection{Population}

This study is made up of a subsample of six patients, all of whom have stroke, regardless of its clinical form. We are investigating about 30 hospitalized pa- 
tients who have undergone clinical research interviews and psychometric tests. The age of the patients varies between 43 and 75 years. The inclusion criteria correspond to the existence of a stroke on the one hand, and the existence of a good general state of cognitive functions i.e. a coherent speech, a conscious and lucid state, somewhere else. In certain manifestations of stroke, we can observe an impairment of cognitive functions. Therefore, we use the MMSE test to make sure when a patient may have a proven cognitive impairment.

\subsection{Research Methods and Instruments}

The methodology used is mixed. It encompasses the clinical method with content analysis, as well as psychometric tools. As for the clinical method, resulting from the medical clinic, it envisages, according to Delay [11] "the conduct in its own perspective and notes as much as possible the ways of being and reacting of a concrete and complete human being grappling with a situation. It seeks to establish in this sense the structure and the genesis, to detect the conflicts and the approaches which try to resolve these conflicts". It allowed us in our reflection to grasp the existential trajectory of the patients, marked by personal, social, family, emotional, professional parameters. The aim is to identify any stressful event in the patient's life, and its psychological consequences, in order to establish a link between the impact of stress and the stroke. In the same vein, Pedinielli [12] perceives the clinical method aiming to "create a situation with a view to gathering the desired information as natural as possible while leaving the subject possibilities of expression". It was used to identify pathological stress in stroke patients and its worsening, even recurrence. So, the inventory of personal, family, somatic, professional and social pathological history, appears, in the context of stroke, as a modality which can determine the factors of disturbance of an individual's personality balance.

We also use data analysis. Our research is part of a qualitative approach to data. These data collected during the clinical interview were entered. We carried out the thematic analysis of the content from an objective, systematic and quantitative description of the observable psychological manifestations, for the purpose of interpretation. The clinical analysis of the patient's speech as well as the psychometric interpretation of the data highlighted the psychic factors, including stress, which contributed to the onset of the expression of the stroke. The failed coping strategies observed were linked to biological risk factors.

\section{Results}

They will first be presented in the form of a summary table from a clinical and psychometric analysis of the clinical case study, then by statistical data. In a second step, we will proceed by a synthesis of these results.

Summary analysis of the clinical case study.

The elements of the clinical interview are shown in Table 1.

The data in Figure 1 and Figure 2 correspond to the results of the psychometric scales used. 
Table 1. Analysis of patient clinical data.

\begin{tabular}{|c|c|c|c|}
\hline & $\begin{array}{l}\text { Biological elements } \\
\text { (from the medical record) }\end{array}$ & $\begin{array}{l}\text { Social elements: personal, family, environmental, } \\
\text { professional, cultural (From the patient's speech) }\end{array}$ & $\begin{array}{l}\text { Psychological elements } \\
\text { (from the patient's speech) }\end{array}$ \\
\hline S1 & $\begin{array}{l}\text { - HTA } \\
\text { - Asthma } \\
\text { - Duodenal ulcer }\end{array}$ & $\begin{array}{l}\text { - } 67 \text {-year-old man } \\
\text { - Death of his daughter, his brothers, his parents } \\
\text { - Two divorces } \\
\text { - Loss of material goods } \\
\text { - Family conflict, feeling of betrayal } \\
\text { - Loneliness }\end{array}$ & $\begin{array}{l}\text { - Trait anxiety, Guilt, Anxiety } \\
\text { - Depression, Persecution } \\
\text { - Gloom, Hostility } \\
\text { - Mourning }\end{array}$ \\
\hline S2 & $\begin{array}{l}\text { - HTA } \\
\text { - Stroke in } 1992\end{array}$ & $\begin{array}{l}\text { - } 57 \text {-year-old woman } \\
\text { - Infertility (had no children) } \\
\text { - Death of his father and his beautiful daughter } \\
\text { - Moral harassment: tension with her stepson } \\
\text { - Marital problems (incessant arguments) } \\
\text { - Dismissal, Unemployment }\end{array}$ & $\begin{array}{l}\text { - Anxiety, Anxiety, Humiliation } \\
\text { - Hyperemotivity (tension) } \\
\text { - Loss of self-esteem } \\
\text { - Frustration } \\
\text { - Depression, Persecution } \\
\text { - Mourning } \\
\text { - Hostilit }\end{array}$ \\
\hline S3 & $\begin{array}{l}\text { - HTA } \\
\text { - Diabetes }\end{array}$ & $\begin{array}{l}\text { - } 52 \text {-year-old woman } \\
\text { - Death of his father } \\
\text { - Forced marriage linked to the culture of origin } \\
\text { - Inter-family conflict: feeling of betrayal } \\
\text { - Intra-family conflict: breaking of ties with children }\end{array}$ & $\begin{array}{l}\text { - Mutism } \\
\text { - Guilt } \\
\text { - Hyperemotivity } \\
\text { - Anxiety, Fear, Frustration } \\
\text { - Depression } \\
\text { - Gloom } \\
\text { - Mourning (linked to his marriage) }\end{array}$ \\
\hline S4 & $\begin{array}{l}\text { - HTA } \\
\text { - Cough }\end{array}$ & $\begin{array}{l}\text { - } 75 \text {-year-old man } \\
\text { - Presence of a lead in his head } \\
\text { - Two suicidal acts committed by his son } \\
\text { - Death of his sister } \\
\text { - Exile (political reason) } \\
\text { - Illness of his wife } \\
\text { - Long period of unemployment: cessation of professional } \\
\text { activity linked to excessive fear of having a car accident }\end{array}$ & $\begin{array}{l}\text { - Anxiety, Anxiety, Frustration } \\
\text { - Depression } \\
\text { - Worry } \\
\text { - Psychological tension } \\
\text { - Mourning } \\
\text { - Gloom } \\
\text { - Post-traumatic syndrome }\end{array}$ \\
\hline S5 & $\begin{array}{l}\text { - HTA } \\
\text { - Depressive syndrome } \\
\text { - Cervical osteoarthriti }\end{array}$ & $\begin{array}{l}\text { - } 76 \text {-year-old woman } \\
\text { - Death of her husband } \\
\text { - Inter-family conflict } \\
\text { - Abondon }\end{array}$ & $\begin{array}{l}\text { - Refoulement } \\
\text { - Anguish, Anxiety, Guilt } \\
\text { - Gloom } \\
\text { - psychomotor agitation } \\
\text { - Mourning } \\
\text { - Depression, irritability }\end{array}$ \\
\hline S6 & $\begin{array}{l}\text { - HTA } \\
\text { - Epileptic seizure } \\
\text { - Stroke in } 2007\end{array}$ & $\begin{array}{l}\text { - } 47 \text {-year-old man } \\
\text { - Motor disability related to his stroke } \\
\text { - Divorce } \\
\text { - Death } \\
\text { - Family breakdown: conflict of rivalry with his sister } \\
\text { - Loneliness } \\
\text { - Job loss related to his first stroke } \\
\text { - Unemployment }\end{array}$ & $\begin{array}{l}\text { - Secondary benefit } \\
\text { - Gloom, Anxiety, Anxiety } \\
\text { - Depressions, Guilt } \\
\text { - Frustration, Narcissistic crisis } \\
\text { - Hostility (linked to rivalry with his sister) } \\
\text { - Vulnerability } \\
\text { - Aggression } \\
\text { - Loss of self-esteem; mourning }\end{array}$ \\
\hline
\end{tabular}




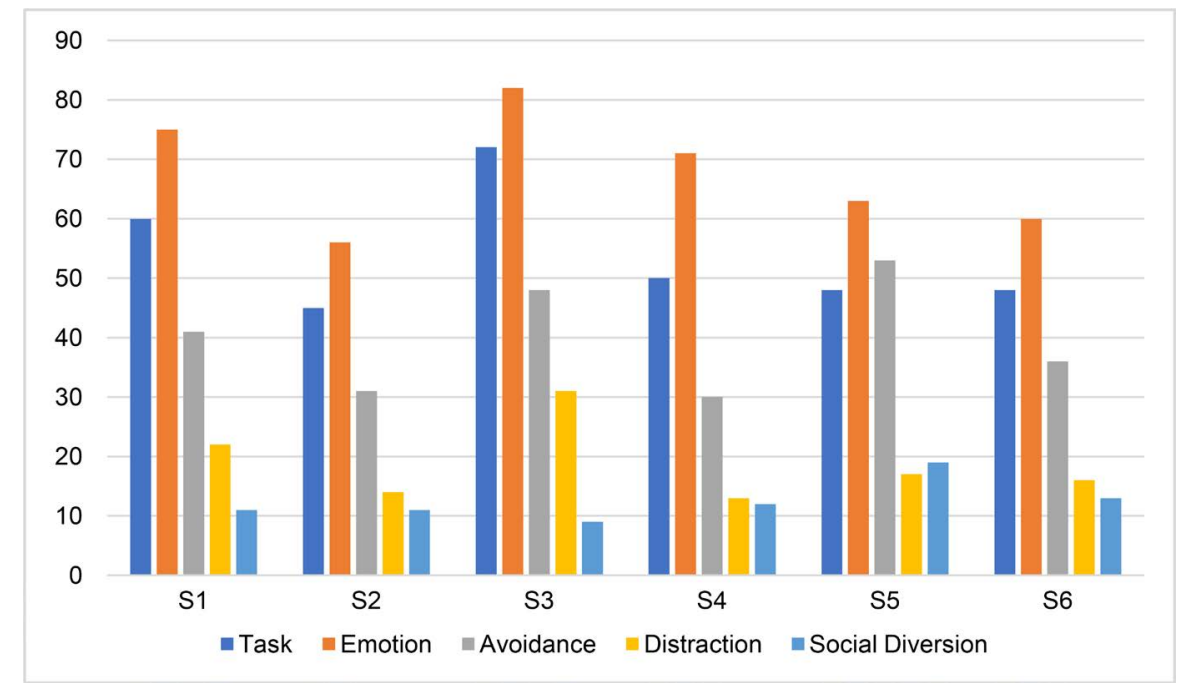

Figure 1. Presentation of the characteristics of the CISS psychometric scale.

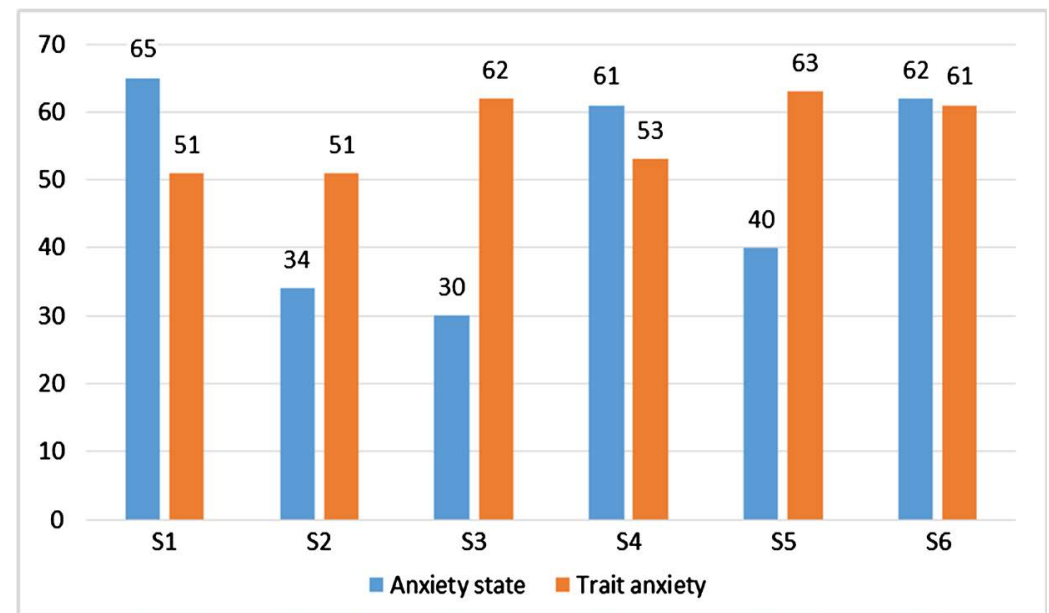

Figure 2. Presentation of the different types of anxiety according to the analysis of the psychometric data of the STAI.

We find that through the summary analysis of the clinical case study, it appears that the stroke, in addition to the specific risk factor, would result from chronic or pathological stress. This stress, it seems to us, would be linked to environmental characteristics but also to the personality traits of individuals and their capacities to manage stressful situations like coping. We detect the mode of coping from the CISS. Coping refers to the emotional, cognitive and behavioral characteristics developed by the subject in the face of stressors or trying situations. Indeed, when we refer to the history and the history of the patients' illness, we observe a series of social, family, personal and professional events which have marked the subject, thus causing psychic suffering. These events would have preceded the occurrence of a stroke. In addition, the indices or psychological elements identified through psychometric tests reveal vulnerable psychological characteristics which would explain the presence of permanent stress. At the same time, in order to assess the impact of stress, we used the scale of Holmes 
and Rahe [13] which consists of indicating the degree of effects experienced by the individual when confronted with life events. According to them, good or bad events are in stressful events and are the source of the disruption of organic adaptation mechanisms. Thus, at the top of this scale, are classified as the most stressful events, the death of a spouse, divorce, separation, the death of a loved one or a serious personal illness. In our study, we note that each patient has experienced these types of stressful events in their existential journey. This implies that their psychological dimension would be particularly affected by a loss of affective object and by a functional loss. We can observe a dysfunction of the psychic defenses, disposing of the person towards a stroke. Likewise, the significant highlights retained such as: social aspect, with unemployment, poverty, loneliness, suicide attempts, loss of property. Regarding the family dimension, we will cite: the death of a loved one, the illness of a loved one, incessant arguments, family tensions, family violence. On a personal level: illness, sentimental disappointment, abandonment; political asylum, migration, alcohol, drugs; and finally on the professional level, we find the dismissal, the professional conflict. These highlights would constitute situations of intense stress which would represent, depending on the psychological significance and the unique history of the subject of psychological assaults. Consequently, these situations would appear as endogenous and exogenous factors which can cause an increase in stress, that is to say, the interaction of organic risk factors and psychological factors as well as social. This interaction would involve the activation of the parasympathetic system which will lead to changes in physiological functioning which can thus promote the onset of a stroke. In this sense, Harrison [14] states that: "when the behavioral responses available to the individual prove to be ineffective in a situation of constraint, or when they are blocked, the organism is in a state of motor inhibition whose persistence can have a pathogenic role for the body".

\section{Discussion}

In view of the results of the case study, we note that the importance of environmental characteristics or stressful life events in the occurrence and course of a stroke translates as follows: the stroke would participate in the manifestation of one or more stressful or traumatic life events. On reading our various theoretical data, we retain that stress plays a determining role in the constitution of psychopathological disorders. Indeed, stress provokes physiological reactions and that the repercussions on the somatic level prove fatal. In the clinical analysis of the cases, we observe that the victims of stroke are permanently confronted with unpleasant and conflictual situations in their life. It would be as a result of these situations that patients would experience a stroke. We qualify them as the psychological accidents of the person's life course, namely: deaths, situations of divorce or emotional separation, unemployment, professional conflicts, abandonment as pointed out by certain authors [8]-[15]. The personal, professional, family, social, cultural, philosophical and religious life history (in the sense of the 
believers) of the patients constituting our study group shows a particular chronic stress in their life course. This stress is identified through psychometric tests: the CISS and the STAI, and through clinical analysis of the data collected during the interviews. Regarding the CISS test, it showed that patients have developed emotion-focused coping modes when faced with stressful situations, which may explain the chronicity of stress. At the same time, the STAI highlights anxiety as a psychic trait which is the psychic consequence of stress. In addition, the clinical elements that stand out in the treatment of patients' speech, express psychological suffering such as depressive and anxiety states, personality disorder [8]-[16]. The existence of this stress is recognized as being involved in the onset of a stroke, thus justifying the link between chronic stress and stroke [16].

Finally, stroke would often appear to be accompanied by psychological suffering. This could be explained by the fact that the subject would not find solutions to personal, social, family, emotional and professional problems, and the repercussions would result in an increase in risk factors related to a healthy lifestyle abnormal. We verify this research hypothesis through three levels that characterize a person's balance: the biological, the psychological and the social.

- At the biological level: there are physical risk factors or biological salient elements, these biological salient elements appear as pathological antecedents. These are pathologies such as high blood pressure, diabetes, cholesterol, obesity. About our sample, four suffer from this history and in particular from high blood pressure. This constitutes psychological suffering from the fact that patients would not find a resolution to their pathological condition. This situation causes stress which Cannon calls "physiological stress" with the consequence of anxious chronicity, considered as a psychic trait [2]-[15].

- At the psychological level, exist alone or in combination: anxiety, anxiety, depression which appear as salient psychic elements which are the source of psychic suffering for the subject [16]. Indeed, the psychometric tests used, the CISS and the STAI, and the clinical interviews made it possible to determine the very frequent psychological state of disrepair of these patients to which is added feelings of anger, guilt, persecution, fear, frustration, worthlessness, loss of esteem, narcissistic crisis, and character disorder such as irritability, aggression. In some patients, during interviews we note the establishment of defense mechanisms such as repression, denial, inhibition. All of its salient psychic elements reflect the stress of patients with repercussions which derive from environmental or social characteristics, which in turn refer to anxious manifestations such as frustration, anxiety, worry but also sometimes rejection which aggravates feelings of isolation, anomaly or even abandonment of the subjects [1].

- At the social level: through the history of these patients, we have listed stressful situations with which each patient has been confronted. These situations experienced by patients are personal, family, professional and cultural. Through the case study, painful events emerge: deaths, emotional separa- 
tions, divorces, professional conflicts, unemployment situations, loss of material or symbolic property, loss of emotional or social ties. These situations can derive as causes or consequences from other facts such as: alcohol and tobacco, and constitute human problems experienced by these patients in their existential trajectory [1].

In the patients considered, in order to adapt to the problems encountered, their organism sets up adaptation modes or strategies to deal with these perceptible ones in the coping strategies that we have evaluated thanks to the CISS. The reaction of organisms following the life events mentioned above causes physiological changes following the activation of the hypothalamic-hypophysio-surenal system. This is the stressful reaction [2] [3]. According to Delay [11] "a given situation triggers a pathological reaction to the event experienced on two conditions: it must have a particular emotional value for the subject, correspond to his disposition; the resources of the organism must be sufficient to adequately integrate the emotional experience into the personality". Thus, the stress caused by emotional and social events comes to affect the biological, which is already affected by its physical and somatic history by increasing the risk of stroke. In this case, this interaction seems clinically justified in the subjects considered, they all declare indeed having experienced a painful impression of physical and psychological exhaustion internal to the onset of stroke. Therefore, we can claim that this working hypothesis seems to be confirmed in a clinical manner.

\section{Conclusion}

Our study shows that stress plays a significant role in the formation and progression of a stroke. Indeed, pathological stress with its psychic consequences such as anxiety states, depressive states and personality disorder, associated with a failure of psychic defenses, would cause a profound disturbance of the subject's ability to adapt, which would be likely to justify the occurrence of a stroke. This brings us back to Selye's theory of general adaptation syndrome (GAS) [3]. Stress would be considered clinically as a psychological risk factor in the same way as vascular risk factors. In terms of psychological recommendation concerning the support of people victims of stroke, it would be necessary for patients to benefit from a systematic and constant psychological care, in order to allow patients to apprehend the psychoemotional mechanisms in connection with stressful situations. This could help restore subjects' confidence and develop their self-esteem. Psychological support would also make it possible to mitigate or reduce the risk of having a stroke. Stress should be the subject of a health concern in order to carry out a primary prevention policy in healthy subjects while developing preventive measures such as psychological care which could help reduce the incidence of stress on the advent of stroke.

\section{Conflicts of Interest}

The authors declare no conflicts of interest regarding the publication of this paper. 


\section{References}

[1] Sounga, D. (2017) Stress et AVC: Approche psychologique des patients. EUE, 81-82.

[2] Canon, W.B. (2002) Pioneer Physiologist of Human Emotions. American Journal of Public Health, 92, 1594-1595. https://doi.org/10.2105/AJPH.92.10.1594

[3] Selye, H. (1975) Stress without Distress. Holder et Stranghton, London. https://doi.org/10.1007/978-1-4684-2238-2_9

[4] Freud, A. (2006) Le moi et les mécanismes de defense. Edition, PUF, Paris.

[5] Lacour, C. (1992) Profil psychologique et réactivité tensionnelle au stress. Thèse de doctorat en medicine.

[6] Everson, R. and Susan, A. (2003) Kuopio Ischemic Heart Disease Risk Factor Study. In: Encyclopedia of Health and Behavior, Sage Publications, TThousand Oaks, 1-2.

[7] Faye, K., Heng, L.H., Collomp, R. and Peroux, E. (2003) Hypertension et Stress. Journal des Maladies Vasculaires, 28, 4-8.

[8] Booth, J., Connelly, L., Lawrence, M., Chalmers, C., Joice, S., Becker, C. and Doughall, N. (2015) Evidence of Perceived Psychosocial Stress as a Risk Factor for Stroke in Adults: A Meta-Analysis. BMC Neurology, 15, Article No. 233. https://doi.org/10.1186/s12883-015-0456-4

[9] (2004) WHO Publishes Definitive Atlas on Global Heart Disease and Stroke Epidemic. Indian Journal of Medical Sciences, 58, 405-406.

[10] Fischer, G.-N. (2005) Traité de psychologie de la santé. Edition Dunod, Paris.

[11] Delay (1997) Abrégé de Psychologie. 3è edition, Masson, Paris.

[12] Pedinielli, J.-L. (1994) Introduction à la psychologie clinique. Nathan, Paris.

[13] Holmes, T.-H. and Rahe, R.-H. (1967) The Social Readjustment Rating Scale. Journal of Psychosomatic Research, 11, 213-218. https://doi.org/10.1016/0022-3999(67)90010-4

[14] Harrison, T. (2013) Principe de médecine interne. Flammarion, Paris.

[15] O’Donell, M.J., Chin, S.L., Rangarajan, S., et al. (2016) Global and Regional Effects of Potentially Modifiable Risk Factors Associated with Acute Stroke in 32 Countries (Interstroke): A Case-Control Study. The Lancet, 388, 761-75. https://doi.org/10.1016/S0140-6736(16)30506-2

[16] Campbell Burton, C.A., Murray, J., Holmes, J., Astin, F., Greenwood, D. and Knapp, P. (2013) Frequency of Anxiety after Stroke: A Systematic Review and Meta-Analysis of Observational Studies. International Journal of Stroke, 8, 545-559.

https://doi.org/10.1111/j.1747-4949.2012.00906.x 